\title{
Tradition and Modernity Stage Performances -- Taiwan Bangzi Opera "Spring on Plum Mountain" as an Examples
}

\author{
Ko Hsiang-Chun \\ Center for General Education National, Ching Kuo Institute of Management and Health, Keelung, Taiwan
}

\section{Email address:}

stellapmo@yahoo.com.tw

\section{To cite this article:}

Ko Hsiang-Chun. Tradition and Modernity Stage Performances -- Taiwan Bangzi Opera "Spring on Plum Mountain" as an Examples. Science Innovation. Vol. 4, No. 4, 2016, pp. 190-198. doi: 10.11648/j.si.20160404.14

Received: May 3, 2016; Accepted: August 18, 2016; Published: August 21, 2016

\begin{abstract}
Taiwan Bangzi Opera "Spring on Plum Mountain" performed in 2014. "Spring on Plum Mountain" adapted from "A-Si-Yi" of Taiwan writer of Wang Cyong-Ling. In the Traditional Chinese Opera stage, show scripts for Taiwan story. Taiwan Bangzi Opera "Spring on Plum Mountain", it combines "traditional and modern". This article will compare the original novel "A-Si-Yi" and the Taiwan Bangzi Opera "Spring on Plum Mountain". Explore opera "Spring on Plum Mountain" how to reset the Taiwanese fiction "A-Si-Yi". Research "Modern novel" adapted into "traditional Chinese Opera", how to break the limit "Cross-cultural Adaptation" and "Cross- the literary style". In this thesis, research direction including inheritance, innovation, culture, theater arts. This article compares and analyzes Taiwan Bangzi Opera "Spring on Plum Mountain", how to reconstruct the original novel. Learn on Taiwan Bangzi Opera localization development. Taiwan Bangzi Opera "Spring of Plum Mountain" changing the way traditional freehand stylized performances on the opera stage. For example, increase in "Taiwanese Ge-zi-xi Opera" and "Movies in the square in front of the temple". How to integrate Taiwan Bangzi qiang and Taiwanese culture? Special attention should be the difference between language and culture. Avoid it will not cause the misplaced of language and culture.
\end{abstract}

Keywords: Taiwan Bangzi Opera, Spring on Plum Mountain, A-Si-Yi, Tradition and Modernity, Localization

\section{傳統舞臺的現代性一以臺灣豫劇《梅山春》為例}

\section{柯香君}

通識教育中心, 經國管理暨健康學院, 基隆, 臺灣

\section{邮箱}

ste1lapmo@yahoo.com.tw

\begin{abstract}
摘要: 臺灣豫劇團2014年度公演大戲《梅山春》, 改編自臺灣本土小說家王瓊玲《駝背漢與花姑娘》中的〈阿惜姨〉, 以傳統戲曲舞臺展演臺灣本土故事。新編豫劇《梅山春》融合了「傳統與現代」, 而傳統戲曲究竟如何突破舊有藩篗、 開創出嶄新面貌。本文主要以臺灣豫劇團新編《梅山春》對照原著小說〈阿惜姨〉，探究豫劇《梅山春》如何超越從 「傳統戲曲」改編為「現代小說」跨文類與文化之限制，如何由文字鬼力幻化成舞臺藝術之手法。本文從承襲與創新、 文化內涵、劇場藝術等層面切入, 分析豫劇《梅山春》如何對原著小說進行重構、解讀, 了解豫劇在臺灣戲曲發展上 之本土性。豫劇《梅山春》在原本單一程式寫意化的舞臺上, 添加屬於臺灣本土歌仔戲, 以及廟口的電影文化。這些 屬於臺灣民間文化體系，在梆子豫劇舞臺上之融合是否恰當，尚有待商榷。尤其應特別注意兩者在語言與文化上的差 異，以避免使觀眾產生語言文化的錯置現象。
\end{abstract}

關鍵詞：臺灣豫劇，梅山春，阿惜姨，現代與傳統，本土性 


\section{1. 引言}

豫劇《梅山春》為2014臺灣豫劇團新編大戲, 與2011 年豫劇百年大戲《美人尖》, 屬同系列之改編劇, 稱其為 「常民豫劇」（豫劇表演與常民生活）。豫劇《梅山春》 改編自臺灣本土作家王瓊玲教授之短篇小說〈含笑〉 [1] （《美人尖》之〈含笑〉) 與中篇小說〈阿惜姨〉 [2]（《駝 背漢與花姑娘》之〈阿惜姨〉)。由劉慧芬教授進行改編, 林正盛導演執導。豫劇《梅山春》將原本兩個不相關的故 事，串連成為三位女子的人生故事。然而「豫劇」、「小 說」本為不同文體, 如何將二者做適切之改編, 其間主線 與旁枝之取捨, 是整體架構最重要的鋪排。此外, 「傳統 戲曲舞臺」與「近現代之劇情」, 二者如何在舞臺上展演, 一方面是傳統戲曲舞臺的「程式性」與「寫意主義」, 一 方面則是「創新」與「寫實主義」, 兩者間之融合度考驗 著編導的功力。

新編豫劇《梅山春》融合了「傳統與現代」, 以傳統 戲曲舞臺展演了臺灣本土故事, 是一齣融合「豫劇、歌仔 戲、電影科技、本土小說、臺灣民謠等跨界美學」之劇作。 新編《梅山春》被譽為「傳統戲曲、小說創作、電影導演 跨界激盪出新火花」, 可見此劇不論在內容上或搬演手法 上有別於一般的演述手法。就體裁而論, 為「戲曲 / 小說」 跨文類之改編; 以內容而言, 為「歷史社會 / 臺灣本土」 之創新改編; 從舞臺藝術手法來看, 則為「傳統 / 現代」 舞臺之相互融攝。

傳統戲曲舞臺向來以簡潔為主，以「一桌二椅」、「虛 擬寫意」為舞臺道具及程式化之演出模式。這 $\lceil$ 一桌二椅」 除了實質之意義外, 更多時候是隨著劇情的需求而變換內 在意涵, 可以是兩張桌子疊高的樓臺, 也可以是一張桌子 的高山, 抑或者是當作床鋪使用等。這種多元變換使用, 導因於傳統戲曲表演形式的「虛擬性」與「寫意性」。然 而隨著西方話劇寫實主義的影響、時代潮流的轉變與新編 劇本題材的加入, 傳統戲曲的表演方式已無法滿足觀眾需 求及劇情內涵, 也因此不得不進行「傳統與現代」之融合, 添加西方「寫實與象徵」之表演元素。

臺灣豫劇團一路走來, 可見其不断精益求精之痕跡, 不僅表演形式、舞臺設計、對於跨文化之新編劇本, 更是 臺灣豫劇團這十年來力求突破的重點, 可以 2000 年《中國 杜蘭朵公主》作為改變的起點。此劇在舞臺服裝設計以及 劇本改編上都呈不同以往的面貌。而後在2009年豫莎劇 《約/束》, 此劇改編自莎士比亞《威尼斯商人》（The Merchant of Venice)；2012年豫莎劇二部曲《量・度》, 改編自莎士比亞1604年的喜劇《惡有惡報》（Measure for Measure）, 連續兩部改編莎劇之作品, 讓臺灣豫劇團呈 現了新的氣象與面貌。

如果「豫莎劇」是豫劇團走向世界化的開端, 那2011 年的《美人尖》與 2014 年的《梅山春》, 則是遇向臺灣「本 土化」的重要指標。《美人尖》與《梅山春》均改編自台 灣本土小說家王瓊玲教授之作品, 主要以臺灣本土環境、 人情、風俗為演述背景。這兩部「常民豫劇」所代表的意 義, 不僅是「新編豫劇」, 更象徵了豫劇團在臺灣發展六 十年來的深刻意涵，也是臺灣豫劇團表明自身「臺灣化」
的聲明。臺灣豫劇團已在臺灣發展一甲子 (1953-2013)， 在許多層面上與中國河南豫劇已有所區別, 臺灣豫劇團曾 表示, 將逐漸朝向「臺灣梆子戲」這樣的稱謂, 表明在臺 灣深根的藝術文化。因此這兩部以臺灣文化為背景新編常 民劇, 不僅挑戰「傳統與現代」融合之舞臺表演藝術, 更 是中國地方劇種深耕臺灣「本土化」的重要演化歷程。

《梅山春》在2014年演出後, 僅有少數評論, 如王妍 方〈心的方向, 家的依歸《梅山春》〉, 從結構、分鏡敘 事手法等進行分析 [3]; 或如紀慧玲〈戲曲 / 映像敘事的 雙重解離《梅山春》〉:

《春》不僅做了映像與戲曲的跨界嘗試, 她再次涉入 跨文化與跨美學的難題, 而如同《美人尖》, 這條「汗 路」一望無盡, 艱辛難解, 唯一能釋懷的, 大概只剩 創作者相信的命運一途而已。[4]

除了從舞臺演出形式對《梅山春》進行剖析外, 同時 也雙重呈現臺灣豫劇團在發展過程中的艱辛。兩者注重的 均為觀戲後的感想評論, 未能與原著進行更為深入之比較 研究。因此, 本文將從劇場面向探討新編豫劇《梅山春》, 從「《梅》劇與原著小說之比較」、「臺灣傳統文化內涵」, 以及「劇場舞臺表演藝術」等, 對《梅山春》進行深入剖 析, 並了解豫劇《梅山春》如何對原著進行重構、解讀, 如何於「小說與戲曲」之間進行符碼轉換, 以挖掘臺灣本 土文學之底蓝, 了解豫劇在臺灣戲曲發展上之本土性。

\section{2. 豫劇《梅山春》之承襲與創新}

\section{1. 《梅》劇之源起}

豫劇《梅山春》是臺灣豫劇團與王瓊玲教授第二部合 作之作品。第一部為2011年《美人尖》, 當時王瓊玲教授 曾如此說: 「海玲老師, 我下筆寫《美人尖》的主角『阿 嫌』時, 心中想的就是您! 您一定可以把阿嫌的愛、阿嫌 的恨; 阿嫌的糾䌂、憤怒; 阿嫌的戰鬥、痛苦……演得淋 漓盡致。」「您絕對會讓阿嫌活過來一不只活在舞臺中、 更永遠烙印在人們心版裡!」因為王瓊玲老師對於豫劇及 王海玲老師之喜愛, 終於促成臺灣豫劇團第一部由臺灣本 土小說改編之新劇《美人尖》, 埋下臺灣豫劇邁向臺灣本 土化之種子。因此, 2014年的《梅山春》, 其演出形式較 以往也有了不同的突破與創新。

臺灣豫劇團自民國42年（1953-2013）到臺灣, 已有 一甲子的歲月, 隨著政府政策之改變, 豫劇團之歸屬也從 1996年前的海軍陸戰隊, 改隸教育部, 附屬國光劇團, 並 正名為「國立國光劇團豫劇隊」; 至2008年再度改隸文建 會臺灣傳統藝術總處籌備處, 改名「臺灣豫劇團」; 最終 於2012年歸入新成立之文化部。一路走來, 臺灣豫劇團設 立於南臺灣高雄左營, 與設立於北臺灣之國光劇團, 成為 了臺灣一北一南兩個重要的傳統戲曲劇團。南臺灣熱情的 陽光, 就像豫劇團身為地方劇種之特質, 擁有豐富的生命 力與野性, 其豐厚的包容性, 展現在對於多元表演形式之 吸收與創新, 以及對於「跨文化」與「跨文類」題材劇本 的挑戰。陳芳教授於〈話說「豫莎劇」: 從跨文化到現性〉 指出: 
「豫莎劇」是臺灣豫劇第一次真正的跨文化作品。演 員不僅必須跨行當詮釋人物, 更細淢精準地反應情緒, 還要轉化傳統程式, 研發新的表演語彙。[5]

自2009年豫莎劇《約/束》, 開啟了豫劇團的不同視 野。然而豫劇團並未滿足於「豫莎劇」與世界接軌的對話, 反而重新思考豫劇團在臺灣的定位, 於是帶著濃厚臺灣本 土味的《美人尖》與《梅山春》終於誕生, 成為豫劇團對 於在臺灣發展內省後的價值定位。

\section{2. 《梅》劇與原著小說之比較}

新編豫劇《梅山春》改編自臺灣本土小說作家王瓊玲 作品, 主要由中篇小說〈阿惜姨〉（阿惜姨與秋月）, 收 錄於 2011 年出版《駝背漢與花姑娘》 [6]，以及短篇小說

〈含笑〉（含笑），收錄於 2009 年出版的《美人尖》 [7]， 兩篇故事改編而成。

在〈阿惜姨〉原著小說中, 以「阿惜姨與秋月」兩者 相互對比, 分別以「同與不同」、「挑」、「奉茶」、「伴」、

$\lceil$ 「憶」、「回娘家」、「子孫事」、「疷」、「喊」、「雨 夜花」、「讓巢」、「救」、「過橋」、「大水」、「渡」 等段落陳述。故事敘述主體在於阿惜姨, 秋月是相對視的 角色, 阿惜姨是年長秋月十六歲的鄰居, 從小看著秋月長 大, 兩人情感可比親生母女。那時阿惜姨已一百零一歲, 秋月已八十五歲。阿惜姨先生「阿田」因肺疼去逝, 因怕 小孩被傳染而拒絕小孩見其最後一面, 因此造成家人對於 阿惜姨的不諒解。而在三個月後的某日, 阿惜姨背著生病 的女兒「阿梅」去看醫生, 途中過橋遇到溪水暴浱, 使阿 梅不幸落水去逝, 這是阿惜姨一輩子的痛, 永遠無法抹去 的悲傷。八年後, 年僅二十歲的大兒子「阿德」, 被徵召 為軍伕, 不幸身亡。十九歲成為葟婦的大媳婦阿珠, 對阿 惜姨始終惡言相向, 最後阿惜姨被迫搬離金鳳寮, 獨自一 人居住，所幸有秋月相依為伴。

秋月故事則是以其身為養女的悲苦遭遇為敘述重點。 自幼被買回家當養女之秋月, 挑起家中大大小的雜事一春 米、飼雞、煮飯、賣简、照顧弟妹, 然而換來的卻是養母 阿粉的虐打，秋月的苦只能怨天，幸而有鄰居阿惜姨的照 顧, 稍減其心中苦痛。直至秋月三十歲, 阿粉才願意讓秋 月嫁給天助。婚後的秋月幸福美滿, 子孫滿堂, 有六個女 兒, 兩個兒子。「秋月」與「阿惜姨」二者成為一個對照 組, 秋月未嫁時的辛苦與婚後的幸福, 對照著阿惜姨家庭 的不圓滿。

在原著小說〈含笑〉一文中, 以全知視角道出含笑與 天助相知相戀, 最終分離, 各自嫁娶。含笑嫁給天生眼瞎 的先生, 並忍受先生酒後的虐打。那年天助二十歲與含笑 相戀，分離後直到三十歲方才娶妻（也是養女），生下八 位兒女, 一直到五十年後, 含笑六十八歲, 自己即將七十 大壽, 兩人透過兒子書信再度聯繫。天助對於含笑的愧疚, 使得天助在往後的五十年歲月中, 背負著無以彌補的虧 欠。

新編豫劇《梅山春》，以「含笑」、「阿惜姨」與「秋 月」三位女臺灣傳統婦女為敘述主線。

阿惜、含笑與秋月, 三位女子、三種情懷、三樣人生。 她們在盤旋疊繞的汗路山徑上, 度過無數的悲歡歲月,
承仰無盡的寒暑風霜。她們都以痛苦的遭遇與堅䓵的 生命力, 釋放所有人間的是非、傷痛、不平與滄桑。 山風雨露, 熾烈鄷陽, 沃灌了花枝蓬勃旺盛的生命能 量, 成就了梅山上朵朵的紛繁春華。(廣告宣傳詞) 《梅山春》一劇主要串連三位臺灣傳統婦女命運, 其 中又以「天助與秋月」之婚姻為劇中結構連繫點。在原著 小說中，「含笑」與「秋月、阿惜姨」是兩個不相關的故 事。小說〈含笑〉文中, 「天助」是含笑相戀愛人, 但卻 因為自己的懦弱, 迫使二人最終分隔兩地, 各自嫁娶; 而 在小說〈阿惜姨〉中，「秋月」先生亦名為「天助」。這 或許是作家王瓊玲刻意安排, 因此, 在《梅山春》劇本重 新編排時, 便巧妙地透過「天助」這個角色將其串連。在 原著小說中, 天助年齡為七十歲, 但《梅》劇中更改為六 十歲。天助與含笑相隔五十年, 而在《梅》劇則為四十年。

豫劇《梅山春》之劇情由三段故事主線依序進行演述, 分別為:

第一段「情人含笑」。含笑為飬女, 與天助相戀而珠 胎暗結, 最後因天助之怯懦, 二人被迫分離, 含笑成為了 別人的新娘。劇情以天助六十大壽將至之日, 其子阿水寫 信給天助開始演述, 天助不斷悔恨與含笑的寬容成為強烈 對比, 是一段無法圓滿之情愛。

第二段「養女秋月」。秋月亦為飬女, 與阿惜姨為鄰 居, 自幼便受到養母的責打與背負家庭重擔, 長大後透過 阿惜姨之撮合, 嫁給天助為妻。婚後家庭生活幸福, 對於 丈夫天助對含笑之虧欠與內疚, 亦從中幫助其父子相認。

第三段「苦心蓮阿惜」。阿惜姨之悲苦, 是無法為外 人言說之苦悶。自丈夫阿田因肺疷去逝, 大兒子阿德無法 見父親最後一面的不諒解, 自此無法再聽見兒子親口呼叫 「娘親」的無奈與傷痛。相繼而來的人生考驗, 小女兒阿 梅在風雨之夜被溪水淹沒, 從此阿惜姨的生命便不再完整。 喪女之痛成為往後吞蝕內心的劇毒, 是「自己對自己」的 一輩子責難。兒子阿德被徵召為軍伕, 戰死沙場, 面對媳 婦阿珠的冷嘲熱諷, 阿惜姨概括承受, 無絲毫怨言。

《梅山春》以柔和順服、無私奉獻的女性特質, 刻劃 梅仔坑女子不同的形象與遭遇。情節大膽採用三重框 架, 一改傳統戲曲直線單一的敘事方法, 突出人物真 實的社會遭遇, 呈現傳統女性「以柔克剛」的生命特 質, 及溫婉內斂的峘新風貌。（廣告宣傳詞）

《梅山春》劇中的三段主線, 基本上與原著小說並無 太大差異, 雖然原著小說〈含笑〉中, 並未明言天助妻子 姓名, 但依照兩篇小說的寫作順序年代來看, 作家王瓊玲 顯然在寫作〈阿惜姨〉時, 是以〈含笑〉為前傳而敘寫。 《梅山春》編劇劉慧芬則提及:

這兩個小説, 其實在原來的時候, 它其實是兩個不相 干的東西, 然後用不同的意識, 心靈的時空, 把它連 結在一起, 所以我們在看這個故事的時候, 它這裡面 有現實的時空、有心靈的時空、有回憶的時空, 有種 種不同意諳流的一個串結, 那麼這個東西, 就是在這 個戲裡面, 在結構概念上, 是一個跟傳統戲曲很不一 樣的地方。 $[8]$

在原著小說中，作家採用了「倒敘、插敘、意識流」 等手法，使得讀者在閱讀上，必需不斷進行時空轉換。同 樣的, 在豫劇《梅山春》裡, 亦以「倒敘及插敘」之方式 
呈現 然而舞臺上太多的場景劇幕之變換是不易的, 因此, 導演林正盛便以影片投影方式穿插進行劇情之推演或補 足小說跳躍的文字敘述。如在阿惜姨喪女與喪夫兩個事件 演述上, 就時間順序而言, 是先喪夫再喪女, 但是劇情搬 演上卻是先演堅女再喪夫, 然後連接大兒子阿德對阿惜姨 的不滿。這種穿插演述, 在小說寫作手法運用上常見, 但 由於舞臺上事件接續發生, 卻反而容易使觀眾產生事件發 生順序之錯亂。

豫劇《梅山春》大致上承襲了原著小說之主旨, 以「阿 惜姨」、「秋月」、「含笑」三位婦女一生之命運為敘述 主軸, 三位主角所呈現之共同點在於對無情命運之「反抗 接受與包容」三階段之轉折歷程。這是人生中不完美的過 程, 但卻是心境的圓滿。「再怎樣怨嗟, 一點也無路用了! 咱是查某人, 查某人的命運好比是油麻菜籽一不挑不揀, 隨便撒就黑白活; 無市無價, 一落地就發芽。認命吧！只 要守本分、認真打拚, 天公伯不會永遠不開眼。一枝草一 點露, 總有一日, 妳會出頭天的。」

\section{3. 豫劇《梅山春》之文化内涵}

新編豫劇《梅山春》改編自臺灣本土小說作家王瓊玲 作品, 主要以中篇小說〈阿惜姨〉, 及短篇小說〈含笑〉 二篇為主，內容以臺灣三、四十年代為背景，陳述臺灣民 間婦女的生存環境及其堅毅的生命性格。

在《梅山春》原著小說中，主要敘寫時間約為 1920 至1950年代, 據蕭相愷所言: 「〈含笑〉篇從天助與含笑 熱戀（1939年）至天助七十壽宴（1989年），跨五十年歷 程。」 [9]而在豫劇《梅山春》裡, 劇幕拉開為阿惜姨與 秋月回憶四十年前「含笑與天助」之情事, 劇中安排的是 天助「六十大壽」，而非七十大壽。不論原著小說或《梅 山春》, 天助與含笑相戀都是二十歲的事。在那個時代, 臺灣尚存有許多的民間習俗。

那個時代的山村風俗民情:〈良山〉的建醮、過火、 「送肉粽」、殯葬; 〈美人尖〉的婚嫁禮俗、民間禁 忌、「洗門風」; 〈含笑〉的沖喜、「擋路」; 〈老 張們〉篇中的臺灣民俗、諺語, ……切都是那樣的 真切！瓊玲把我帶回了經他濃縮的歷史之中, 讓我沉 重, 讓我傷悼, 讓我顫慄, 讓我振奮。[10]

種種的民俗禁忌, 帶來的不是喜氣的運勢, 而是一連 串悲傷運命的開端。這些民俗正是最貼近臺灣社會底層百 姓生活的寫照, 而豫劇《梅山春》也是秉持原著小說的精 神, 期盼更融入臺灣早期社會, 見證豫劇團在臺灣的六十 年歲月。

\section{1. 堅毅與寬容--臺灣傳統婦女}

豫劇《梅山春》以「含笑」、「秋月」及「阿惜姨」 三位婦女之人生命運為鋪敘重點。所刻畫的是臺灣傳統婦 女最大的特點:「堅毅性格」與「寬容胸襟」。在面對命 運無情的擺布, 沒有怨對, 有的只是默默的逆來順受, 縱 然有心反抗, 亦抵擋不了社會的吃人禮教與習俗束縛。在 豫劇《梅山春》的「宣傳廣告」詞如此描述:
含笑、秋月與阿惜, 梅山嶺上三種樣態的女性, 在盤 旋疊繞的汗路山徑上, 度過無數的悲歡歲月; 梅山女 子與汗路, 共築了一條難以分解的生命途徑……梅 山女子化悲情為力量 揉摧折為大愛, 她們擁抱痛苦、 和血吞淚，將生命中無法克服的難題，提煉為人世間 真善美的故事。梅山女子不再只是梅山嶺上一群少數 女性的生活紀錄, 而成為所有受傳統社會影響命運的 女性, 對生存意義的思索與對話。（廣告宣傳詞）

雖以梅山女子為縮影, 但投射的是臺灣早期傳統婦女 「生命愺性」與「生存意義」, 而其背後得以支撑的就是 「家庭」。在《梅山春》劇中, 表達了臺灣傳統婦女「對 家庭的渴望與付出」, 即使面對再多的苦難, 只要能成就 一個圓滿家庭, 一切的辛苦也就值得了。在面對養父母的 無情與天助的懦弱, 婚嫁後的含笑選擇的是原諒, 以寬容 取代怨對, 在阿水寫給天助的信中提到:

娘說生的放一邊, 養的大過天, 我一直沒有敢認你, 去年冬天, 我阿爸過世, 秋月嬸託人帶信, 要我給您 拜壽, 明天是您的六十大壽。

她說, 孩子, 任何傷口都會好的, 除非你一直不斷地 割它, 人心裡的怨毒就像這道傷痕, 如果一直存在心 裡, 它永遠都好不了, 那可是害慘人一輩子的。…没 有恨, 才能快樂活著。( 《梅山春》)

面對當初天助的怯懦, 含笑不埋怨, 反而感謝天助曾 給過她家的夢想, 展現了臺灣傳統婦女堅韎寬容的心胸。

而天助的妻子秋月，面對丈夫過往的情事，亦秉持無 私的精神, 使其父子得以享受遲來的天倫之樂。在劇中秋 月唱道:

四十年來如一夢, 傷心故人魂牽縈。兩地離愁淒淚哽, 愁腸寸結恨餘生。(你的心裡永遠都是她。) 羡含笑, 你心頭長憶相思影。憐含笑, 命如游絲此生堪驚。惜 含笑, 生子難見親父面。音書阻絕四十春, 秋月衷心 把夫敬, 六十大壽父子團圓, 心願成全。(《梅山春》) 秋月內心是複雜的, 一方面為天助與含笑戀情深深感 動, 但一方面卻哀傷含笑在天助心中佔據了四十年的時間。 然而秋月還是促成天助父子相見, 實屬難得。劇中呈現了 女人之間的「相知相惜」, 以及「寬容大度」的傳統美德, 不僅是原著小說的主旨, 也是《梅山春》劇中的精神主體。

在《梅山春》劇中, 阿惜姨的一生則是承載了多樣的 苦難, 面對接踵而來的命運考驗, 阿惜姨始終寬容以對。 喪女、舗夫之痛、兒子的不諒解、媳婦的怨對, 使得阿惜 姨的人生, 如同汗路, 崎嶇艱困, 但這些苦難也一一往肚 子裡吞，沒有任何埋怨。

在《梅山春》劇裡, 展現了臺灣傳統婦女的「愛與包 容」。如秋月對於養母阿粉之情感, 面對養母自幼的苛刻 與虐打, 在秋月出嫁養母生病後, 依然回家探望照顧; 又 如阿惜姨對於長子阿德的不諒解與媳婦阿珠的埋怨, 都無 怨的一一承受; 或如含笑對於天助的懦弱、養父母的狠心 安排、或者丈夫的虐打, 也用愛加以化解, 因為「人心內 的一點點怨毒, 是會害慘人一輩子的。」

臺灣傳統婦女, 念茲在茲的是家庭的圓滿, 對家庭完 整的渴望, 所以面對再多的責難與困境, 都可釋懷以待, 無怨無悔。而《梅山春》中婦女的包容與勀性, 不僅是臺 
灣傳統婦女的縮影, 也是王海玲老師辛苦的生活歲月, 更 是臺灣豫劇團在面對臺灣多元文化所展現的包容性。

\section{2. 破除與消災--養女習俗}

豫劇《梅山春》，「含笑」與「秋月」均是養女身分， 也是他們悲苦生活的源頭。「含笑」與「秋月」同為養女, 相同的是在收養家庭所遭遇的艱困生活, 不同的是嫁娶後 的婚姻生活。

在〈含笑〉文中寫到了臺灣婦女的命運。含笑當初便 是因為「沖喜」而成為養女, 「抱我來沖喜啊！當時, 我 大兄才三歲大, 病得只存一口氣絲, 童乩講要抱一個查某 因來沖喜，才會好起來。」所謂「沖喜」，在臺灣民間傳 統習俗中, 為久病不癒的病人, 透過喜事來沖掉不好的運 氣, 以達到治療醫病的效果; 或者以結婚喜事給生病之父 母沖喜。文中含笑因為欲替臥病在床的大兄沖喜, 因而成 為養女, 更明確的說法應該是當做「童養媳」。童養媳即 「媳婦仔」, 乃是父母為將來給兒子當妻子而收養的異姓 幼女, 通常以兩三歲為原則。等兩人達到適婚年齡, 便順 其自然「送作堆」, 完成「戶內婚姻」。[11]因此, 含笑 自幼便已決定了將來婚配的對象--大兄，所以當含笑「未 婚懷孕」, 養父母自然是怒不可遏, 惡意為難, 硬生生拆 散含笑與天助。

你看！你們攏總來看！這是啥態度？我飼養伊十八 冬, 十八冬咧! 未嫁即去討「契兄」, 削世削眾, 削 我十八代祖公的面底皮! ……

莫怪呵！莫怪！叫阿旺嫂來做媒人。「肥肉吞入肚, 嘴才唸阿彌陀！」哼! 不知死活的臭小子, 春秋美夢 還真是敢做！我不會讓伊暢心滿意的。[12]

最終, 含笑嫁給了一位天生眼瞎的男子。這正是養父 母的不諒解、不甘心, 也是身為養女含笑的悲哀命運, 其 無法獲取幸福的背後, 是人性黑暗面的作崇。

在舞臺上, 豫劇所使用之言語更為俚俗, 面對旺嬸替 陳家前來提親, 含笑養父終於了解二人「偷來暗去」的情 事。

含笑養父: 問了半天，這狗賤人一句實話也不說，原 來是陳家這狗雜種幹的好事。我…我非宰了他不 可。……他們陳家破了咱家的門風。壞了咱家的親事, 這輩子想成親, 他們休想。……旺嬸, 你在這山前莊 後, 仔細地打聽打聽, 個人家離此是越遠越好, 只要 給得起豐厚的聘禮, 管他是聾、是瞎、是駝背、是癱 子, 含笑通通嫁, 就是不許嫁陳家。(《梅山春》) 含笑的「養女」、「童養媳」身分, 在家中一點地位 也沒有, 而養父母面對含笑的僭禮行為, 亦不存有絲毫的 憐憫之心，甚而氣忿含笑敗壞門風，不讓含笑得到該有的 幸福。臺灣早期社會收養女之行為, 一般可分為兩種情況, 一是純粹收為養女, 即當作女兒收飬, 或因應農業社會人 力需求, 收養女可以幫忙繁重家務與農事; 一種是消災之 用, 通常是收養成為「媳婦仔」, 目的在於消災沖喜。

此外, 含笑養父還是一位重男輕女的人, 「阿爸才不 會操煩我哩! 伊只疼我的大兄和小弟, 講啥查某因是敗家 產、賠錢貨, 早慢要嫁人做媳婦。」[13]臺灣早期社會, 重男輕女, 女兒是賠錢貨, 養父母辛苦自小拉拔長大的「媳
婦仔」, 怎麼可以輕易的為他人作嫁。不論是「養女」還 是「媳婦仔」, 從小就必需負擔家中一切大小雜務, 「拼 生拼死在做穡: 撒菜籽、踩水車、插稻积、割麻竹简, 挑 重擔去梅仔坑市場賣。」「秋月」的養女生活便是在做不 完的家事中渡過。

每位養女在面對養父母家庭之磨難時, 皆發出對生命的 感嘆, 感嘆被親生父母遺棄的悲慘遭遇。如秋月面對養母每 天交待做不完的肩頭重擔與沉重壓力, 發出了怨對之言:

他問阿惜姨, 也問老天爺: 為甚麼要讓她出生? 為甚 麼要讓她被收養? 如果生母不要她, 何必叫產婆剪斷 臍帶? 拿起血淋淋的胎衣往小臉一蒙, 不就一了百 了? [14]

而秋月則是在孕育生命後, 想起當初自己來到這世界 時的感觸。

朦朧中, 含笑渴切地想起生下她的人一那一對從小浮 現在她睡夢裡、淚霧中的貧困夫妻, 把她帶到這個世 界的陌生人。十月的珠胎, 換來一疊錢、一袋紅糖、 幾厅麵線。送走她時, 是骨肉相離的悲愴? 還是生計 減輕的慶幸? [15]

這是身為養女的命運, 是臺灣傳統社會下婦女的悲苦。 《梅山春》劇中透過演員表演的說白唱腔, 亦深刻的表達 出已被注定而無法改變的命運。

\section{3. 救贖與圓滿--文化習俗}

豫劇《梅山春》裡的三位婦女, 可說是臺灣民間習俗 下的犧牲者, 造成其悲慘命運背後的推手, 皆導因臺灣早 期的社會文化。如含笑的「沖喜」童養媳, 天助的「母茂 三年」內不能娶妻、秋月的養女生涯等。

在重男輕女父權下的臺灣婦女是悲苦的, 婉君推薦序 提及: 「〈含笑〉裡, 被父權與私心拆散的年輕男女在情 愛的廢墟中委屈求生, 因為能放下過去, 所以得以釋放自 己。」[16]民間「擋路」習俗則在含笑的出嫁過程中, 亦 彰顯了臺灣傳統婦女在父權社會底下的悲苦。

男人道底好辦些, 較容易被寬恕, 不需要走一雖然,

留下來不一定比離開好過。

然而, 女人真的永遠回不來了。花轎一離地, 含笑養 父就在門口壓下一塊大石頭, 執香立誓: 「石頭擋門 口, 新娘不回頭; 石頭擋廳堂, 新娘放水流。」 這叫「擋路」--被擋路的新娘, 才真正是被撥出去, 任人踐踏的水。[17]

在傳統社會中對自己親生子女尚且如此, 更何況是抱 來買來的養女, 如何有公平的對待。這些女子對於自身命 運亦了然於心, 「她們全是天養的一粗手粗腳、無病無痛, 比男人還耐操耐勞。」

《梅山春》劇中的女子生命是悲苦的, 編劇家劉慧芬 教授言道:

但是人面對痛苦以後, 關鍵是我們用什麼方法來面對 我們痛苦, $\cdots$ 其實是傾向是走向一個比較寬容的, $\cdots$ 不像我們在「美人尖」看到那一種, 很無可退避的空 間。…人生就是這麼一回事, 你要不要放下, 你要不 要選擇一個愛的感覺, 你要不要選擇生命的一種圓融 的境界, 那是你的智慧判斷, 我不會告訴你這個事情 
是善的, 這個是惡的, 你應該怎麼做, 那是我們講的 高臺教化, 那是比較傳統的一種戲曲表演, 但是這個 故事, ……我們怎麼去感受, 我們對生命這所有事件 的大大小小, 在我們身上發生的意義, 你要用什麼態 度去接納它, 這是你自己的人生智慧, 這三個女人選 擇的是放下、自由, 然後自在, 然後讓那個愛的感覺, 自然的流露在她們的心裡面，同時也傳遞給觀眾。［18］ 面對生命中不可違逆之悲苦遭遇, 惟有透過智慧判迦, 選擇放下, 才能獲得生命之圓融。這是劇中三位主角的選 擇, 是臺灣傳統婦女試煉後的決定, 也是劇中所要告訴觀 眾的人生道路。

「奉茶」是臺灣早期農業社會的文化習俗, 為過路人提 供茶水。阿惜姨的奉茶是從那件河邊慘事開始, 持續近七十 年。「從昔日金鳳寮的汗路邊，到現今梅東村的巷子口，除 了刮大颱風的日子, 其他無論是過年過節、晴天陰雨, 這樣 子的奉茶, 已持續七十多年了。」始自阿惜姨小女兒阿梅落 水後, 從二十八歲到一百零一歲 (小說裡的年紀)。奉茶背 後所承載的意義究竟為何? 是仁慈? 還是贖罪?

其實也有滿多的奉茶, 跟阿惜姨有一點像, 她心裡面 是有一個, 很強的那一種生命的不圓滿。(林正盛) 在這個戲裡面, 她的奉茶, 她把她對於親人的愛, 把 它擴大, 變成她對所有的, 她相關的, 不相關的人, 經過她家門口的人, 都能夠感受到這份愛。從這個奉 茶的動作裡面, 來表現出來, 所以我覺得奉茶這個意 思, 其實是阿惜姨自己的一個自贖, 跟自我提升的一 個動作。所以你可以看到, 這一個簡單的動作, 其實 是蘊含她內在很複雜的, 也很深的內在的一個情感, 跟一個非常高的一種理想的一種期待。（公視《梅山 春》訪談)

傳統奉茶行為, 早期或為翻山越嶺往來之路人提供方 便茶水, 但在小說與《梅》劇中, 卻帶有「救贖與祈福」 之意藴, 是對生命的另一種轉化與提升。阿惜姨的悲苦生 命, 是無解的, 是命定的, 因此阿惜姨只能提升自己對於 女兒阿梅的愛, 給予往來的路人, 這是一種自贖, 也是愛 的轉移, 對於阿梅生命消逝的另一種期待。

豫劇《梅山春》之主題思想可包涵三大層面, 「人生 選擇」、「愛與包容」以及「生命圓融」。從「人生選擇」 來看: 人生本是一條不斷選擇的道路, 是與非、東與西、 南與北, 一但選定便難已改變, 因此時常可聽見「早知 道…」、「就不會…」, 在《梅山春》三位女主角生命中, 很多選擇不僅是自我決定, 也是命運安排, 如果當初含笑 沒有選擇與天助偷嘗禁果, 或許不會珠胎暗結, 不會惱怒 養父母, 而將其嫁與一位殘缺之人; 如果當初天助選擇與 含笑私奔, 或許兩人就可以幸福美滿, 而天助也不用帶著 悔恨走完一生。然而這些都只是或許, 相反的選擇亦未必 是甜美的果實。

\section{4. 豫劇《梅山春》之劇場藝術--象徵與寫意的衝 突與調和}

在傳統戲曲舞臺上, 主要以虛擬之程式化身段為表演 藝術, 演員透過身段作表, 將實體場景虛擬地展現, 將所
欲呈現之喜怒情感, 以聲音美化的方式傳達。傳統戲曲舞 臺不需真實的物件堆砌在舞臺上, 在舞臺整體設計上, 簡 單而靈活, 與實體話劇繁複之舞臺造景設計, 是不相同的。 然而在傳統戲曲舞臺上, 演出之劇情多為古代劇本，在服 裝及舞臺設計上, 較無違和感, 而現今戲曲為求創新與現 代融合, 勢必於表演形式上力求突破, 一來為傳統戲曲添 入更多變化, 使傳統與現代相互融合; 二來為傳統藝術, 開創新視野, 使傳統戲曲與時具進, 吸引更多觀眾, 而非 成為束之高閣的文化藝術。臺灣新編豫劇《梅山春》正是 在這樣的思維上，開啟了傳統豫劇梆子戲的多元內涵。

\section{1. 梅山汗路之象徵}

《梅山春》整體舞臺設計以「汗路」形象為主。「汗 路」對梅山有著重要的象徵意涵, 在王瓊玲原著小說《駝 背漢與花姑娘》其附標題便是「汗路傳奇」。於原著小說 中寫道:

由梅仔坑市集向著十多個山村輻射開去的汗路，是兩 三百年間，先民們挑著重擔、淌著汗水，上下海拔一 千多公尺, 穿山越嶺所踩踏出來的謀生小徑。陡峭的 石階、青苔的土路, 共構出一整個梅仔坑鄉的艱困與 坎坷。[19]

這條汗路是嘉義梅仔坑鄉的謀生小徑, 積累的是先民 兩三百年來所踩踏而成的, 它不是平坦的大道, 而是陡峭 崎嶇的山路, 是百姓辛苦生活的象徵, 也是人生起伏旅途 的縮影。「小時候, 我走過梅仔坑蜿蜒崎嵓的汗路, 知道 所謂『一坎到肚臍、二坎到目眉』的險峻, 真的一點也不 誇張。」[20]

在豫劇《梅山春》的「宣傳廣告」詞亦如此描述:

梅仔坑的女性生活脫離不了「汗路」, 那蜿蜒崎嶇的 山路野徑, 是當地女子與外界隔絕及精神禁錮之象徵, 同時, 也成為她們在心性上自我淬鍊的必要過程。（宣 傳廣告詞)

汗路形象, 不僅在地理形勢上隔絕了梅仔坑與外界的 聯熬, 也象徵了當地女子精神的禁錮; 走在汗路上, 不僅 是梅仔坑女子的辛苦生活寫照, 也是臺灣早期傳統婦女一 路走來的生命淬鍊與昇華。編劇劉慧芬在接受公視《梅山 春》訪談時便言道:

汗路, 是這個故事的一個時空背景, 最主要的一個重 點, 那麼這一群女人, 他們的愛情故事也好, 家庭故 事也好, 都在這個汗路上發生, 而且這是梅山春, 他 們現在本地人，本來就有的一個文化的背景。所以這 一群人, 在汗路上來來去去, 秋月春風, 颷風下雨, 陰雨晴天都不管, 在這個上面, 他們發生了他們所有 人生的故事, 所以這個時空被點出來, 是有他的必要 性的。所以它暗喻了這三個女人的生命歷程, 那它當 然也點出了, 在嘉義梅山村這裡面, 所有男男女女, 他們的生活環境, 就是在這個汗路上發生的。（公視 《梅山春》訪談)

正因為汗路所承載的深刻意涵, 透過「汗路」串連起 三位梅山女子的人生, 所以在豫劇《梅山春》舞臺設計上, 便將「汗路」做為主要場景設計, 在舞臺左側搭建兩方出 口的「汗路」, 象徵人生黑白是非的選擇。這條汗路是臺 
灣早期農村發展的辛苦象徵, 是梅山婦女堅毅性格的延伸, 更是人生道路上的起伏與悲喜。如同舞臺上的唱詞:「梅 山春，風來雨去汗路苦。」

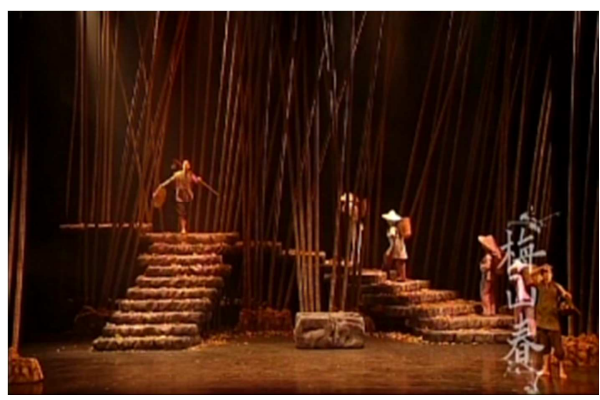

圖1《梅山春》舞臺「汗路」設置。

然而如此寫實的舞臺設計, 對於以寫意為主的傳統戲 曲舞臺, 究竟是加分或減分？舞臺的搭建，起了層層的階 梯, 這些高低不平的設計, 或多或少阻斷了傳統戲曲舞臺 的流動性，當演員於舞臺上展現身段作表時，腳下的高低 臺階, 造成演員更多的阻礙, 演員必需同時注意身段, 腳 下臺階, 以及唱詞, 實是增加了演員的負擔。觀眾在面對 阿惜姨抱女過河看病時, 所擔心不是阿梅掉入溪流之中, 反而是害怕演員踩空滾落, 演員身上背著竹簍, 手上抱著 女兒, 既要唱, 又要身段, 實是令觀眾擔心又害怕, 而無 法全心投入欣賞。

雖然《梅山春》劇場受到寫實主義與象徵手法之影響, 但傳統戲曲舞臺之身段作表依然是基本元素, 不可偏廢。 在含笑前往求救天助與其一起私奔時, 夜路行走於梅山山 路, 就是寫意的演述。透過含笑肢體動作, 夜裡趕路之情 狀便呈現在觀眾眼前。

劇中主要有兩個段落為傳統身段演述, 一是展現梅山 男子辛勤耕作, 一是含笑飬父追打天助。豫劇《梅山春》 必竟是傳統戲曲, 而傳統戲曲所該具備之歌舞表演與雜技 亦不可缺少。

\section{2. 電影手法之互補}

現今傳統戲曲舞臺上, 不再是一桌二椅, 而是結合了 科技影像, 在《梅山春》一劇中, 導演林正盛突破了以往 簡潔的傳統戲曲舞臺, 而以電影手法, 增添此劇舞臺藝術 之可看性。在舞臺設計上, 豫劇劇組團隊還實地帶領演員 至「嘉義梅山鄉太平村」出外景, 主要為拍攝梅子坑村婦 挑擔走汗路的驚險畫面, 並將影片以投影方式穿插於舞臺

上，為演出時的背景畫面。

在原著、編劇與導演的努力構思下, 《梅山春》劇本 融合了電影的映像語言, 將小說人物年老時期的回憶、 複雜的場景事件, 全部串連起來, 將在舞台戲曲的演 出形態外, 以電影拍攝的手法, 環迴交錯呈現。林導 演將以鏡頭的設計與時空變化，促進觀眾的情緒的聯 結與感官上的互動效果。（廣告宣傳詞）

新編《梅山春》在劇場整體設計上，確實較以往傳統 戲曲舞臺複雜, 在臺灣廟會文化中, 廟埕的「電影播放」 與「歌仔戲搬演」, 都是臺灣早期百姓的生活, 而在《梅 山春》劇中, 卻將此三元素堆疊在一起。這種手法運用貫
串《梅山春》整齣劇作, 除了頭尾之外, 還有三段拍攝歌 仔戲演出的電影畫面, 主要呼應三位故事主角的人生。

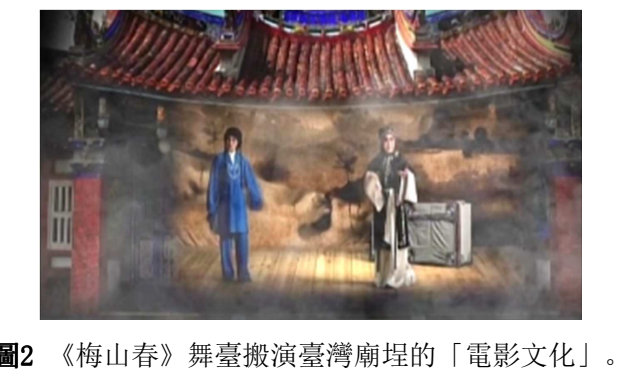

第一段「情人含笑」, 電影以「梁祝」故事暗喻, 當 中所欲表述的是對「梁祝生死情愛」的反差, 以梁祝二人 終究化成蝴蝶雙飛, 暗喻了含笑與天助兩人情愛的消離。 最後同樣以梁祝歌仔戲結束第一段。

第二段「養女秋月」，重點在於養女秋月與養母阿粉 之間的關係, 而非秋月與天助, 因此在電影片段選取上以 「三娘教子」相比擬, 「所以這個『三娘教子』跟現實的 養母去打養女的, 它又營造了另外一個回音出來。」（劉 慧芬) 而當中穿插一段秋月看電影時之感傷, 一方面為天 助與含笑感情不圓滿表達哀傷, 另一方面則輕描淡寫丈夫 對於含笑不能忘情的自憐, 主要用於補強第一段落「含笑 與天助」之愛情遺憾。

第三段「苦心蓮阿惜」, 電影片段選擇「泥馬渡康王」, 主要描繪的重心在於阿惜姨對於將小女兒阿梅掉入溪裡 的哀傷。電影的泥馬䭾起昏迷的康王, 渡過滾滾黃河, 但 誰可以拯救阿惜姨的小女兒阿梅, 歷史的圓滿結局, 卻道 盡了阿惜姨的滿腹心酸。這哀傷是一輩子的, 也是阿惜姨 往後人生無法抹滅的痛苦。

在原著小說中，僅描述「泥馬渡康王」，其餘二者是 編劇家另外編排的。

在原著小說中, 王瓊玲教授使用了最具代表性的臺灣 歌仔戲為故事中人民群聚廟會的生活寫照, 並且將歌仔戲 演述之內容連結到劇中之敘述主體, 而《梅山春》劇中, 則進一步使「歌仔戲、電影、戲劇」三者呈現「互補」功 效。三段歌仔戲演出, 主要以放映電影的方式呈現, 應當 是考量舞臺演出上的局限, 因而以電影形式代替實體演出。 紀慧玲在〈戲曲 / 映像敘事的雙重解離《梅山春》〉中提 到: 「這類平行、補述、轉接, 成了《春》相當奇特的敘 事方法, 形成一套兩種媒介——寫實、一寫意—一共同 說一個故事的新穎敘事體。」[21]編劇劉慧芬亦云:

所以這個影像有點像回音, 䘽托得非常有韻律 感……戲裡面三娘對於她的孩子是愛, 所以這個「三 娘教子」跟現實的養母去打養女的, 它又營造了另外 一個回音出來一個是她現實在看戲的, 過去那個悲慘 的狀態,一個是戲中戲的狀態, 所有它有三個層次, 這三個層次是不可同時在舞臺上傳遞出來的, 所以它 全部疊在一起, 那個戲劇力量跟張力, 還有那個影響 的氛圍是很大的。 (公視《梅山春》訪談)

電影映像的使用, 創造戲曲舞臺上同時展現多元視角 與不同層次的意涵, 透過連結、平行、補述三種角度所營 造出來的戲劇張力是強烈且憾動人心的。 
而電影導演出身的林正盛, 對於將傳統戲曲舞臺與電 影相互結合，則是企圖呈現一種更為抽象的概念。

舞臺是一個虛擬的空間, 某種程度是虛擬的, 因為它 不是跟真實一樣的東西, 是一個被戲劇化之後的空間, 所以第二次在做「梅山春」的時候, 我就讓舞臺那個 影像更抽象, 做更抽象的一種呈現, 然後讓它跟舞臺 結合得更好, 幫助把舞臺用影像化得東西, 我用電影 的那種表演的方式, 去帶他們更多內在的東西出來, 角色更強以後, 在去走身段, 傳統戲曲因為它很奔放, 應該比較接近現代的戲的時候，其實我們演員轉換的 空間。（公視《梅山春》訪談）

舞臺劇其實很有趣, 它有一種現場當下即逝的感覺, 就是那一種人在環境裡面, 所展現出來的生命的力量, 那個生命力量就包含著, 他可能所面對的辛苦、悲傷。 （公視《梅山春》訪談）

在《梅山春》舞臺上, 處處可見電影之表現手法, 為 此《梅》劇一行人還至嘉義梅山出外景, 將所拍攝的實際 畫面, 於舞臺上以投影方式呈現。

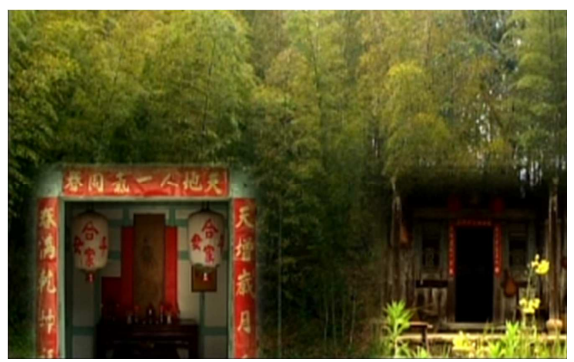

圖3《梅山春》將外景拍攝畫面投影於舞上。

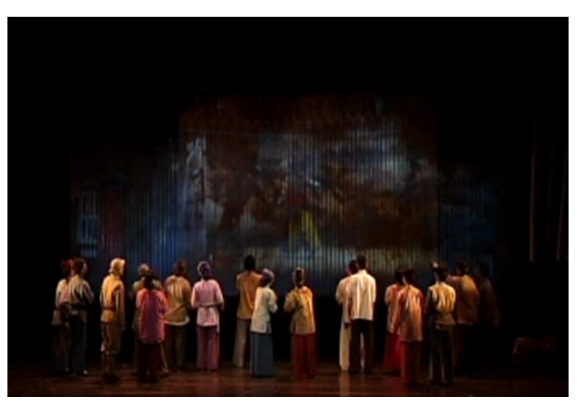

圖4《梅山春》舞臺上運用投影技法。

此外, 以往虛擬寫意之道具, 亦以實體面貌出現, 如 阿粉臥病在床, 以及阿德生病的床舖皆以實體呈現, 而非 以往演述古戲碼時所採用由一桌二椅簾幕之形式, 此乃受 限於劇情時代所導致。

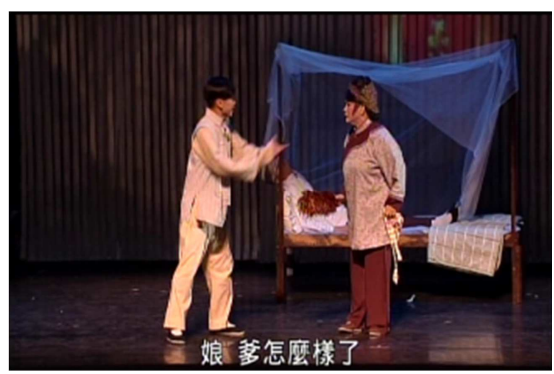

圖5《梅山春》舞臺上的寫實設計。
傳統戲曲舞臺的敘述結構，原本的「一桌二倚」、「虛 擬符碼」、「程式化身段」, 在《梅山春》劇中著實明顯 的減少了。整體舞臺以「梅山汗路」為主體, 表述了強烈 的象徵意涵, 然而實體的山路架設在舞臺上究竟恰不恰當? 當演員在汗路上辛苦的表演身段是又是否仍保有其流暢 性? 這都是臺灣傳統戲曲在面對新創劇本, 以及多元舞臺 設計值得深入思考之議題。

\section{3. 戲中有戲之隱喻}

如前所述, 在《梅》劇中大量使用了「電影」映像與 $\lceil$ 歌仔戲」之故事內容, 明顯地以「戲中戲」之編排方式, 架構整齣劇作。當劇幕一拉開, 先由阿惜姨與秋月二人對 話, 帶出四十年前「天助與含笑」的不圓滿愛情, 而舞臺 上投影方式, 架設起臺灣早期廟會電影播放場景, 一家大 小搬著椅子到廟前廣場看戲, 阿惜姨說到「當年我可是親 眼看見這件事的, 比這臺子戲還要精彩。」接著螢幕上演 出的是「梁山伯與祝英台」歌仔戲, 隱喻著第一段故事「情 人含笑」。

直到劇終, 舞臺上再次出現廟前廣場。

阿惜姨: 「這人生就像是一臺戲, 不管你喜不喜歡, 還是得把它演完。」

秋月: 「是啊! 我們天天來看戲, 就像看著自己演戲 似的, 人講戲棚頂有的, 戲棚腳就有啦!」（《梅山 春》）

前後呼應的戲中戲概念, 不僅傳達了「人生如戲」的 戲劇本質, 對於劇中婦女的苦難遭遇, 也凸顯了人生痛苦 的根源, 皆起自人類自我心念, 如同三位主角, 在面對命 運的捉弄, 惟有內心自我的救贖, 才能解脫悲傷, 成就圓 滿。

歌仔戲本已具備「人生如戲」之意涵, 而以電影呈現, 則是更加強化「戲中戲」之概念。當阿惜姨與秋月一同看 歌仔戲時, 歌仔戲又是電影之劇本, 如此安排對於整齣劇 作而言, 強化了劇中的主旨, 彷彿有著訴說不盡的哀傷與 命運的輪迴。

\section{4. 語言文化之錯置}

臺灣豫劇源生於中國河南, 為梆子聲腔系統, 與各地 聲腔最大區別, 不僅在於樂器文武場之演奏, 其歌唱表演 技巧、舞臺身段演述上亦有所不同, 但更重要是帶著濃厚 的地方語言特質。臺灣豫劇團自中國來臺灣發展已有一甲 子, 其在表演藝術、文武場、以及劇本演述各方面, 早已 加入許多臺灣本土特質, 因此當臺灣豫劇團要上演深具臺 灣本土特色劇作時, 如何使來自河南地方語言與臺灣本土 語言文化相互融合, 是演出時一個重要的問題。然而這個 問題在《梅山春》演出時, 確實顯得格格不入。在原著小 說中, 以臺灣早期農業社會為主, 而嘉義梅山村一帶, 主 要語言為臺灣本土閩南語系, 村人農閒時的休閒娛樂, 是 於廟前廣場前觀賞歌仔戲的演出。在舞臺演出時, 臺上為 純正閩南語, 臺下卻是河南話, 形成了地理環境的錯置, 而這樣的「錯置」卻是一個無法改變的錯誤。畢竟在傳統 戲曲演出時, 每一個地方劇種最大差異便是語言上的相異 
性, 因此以河南豫劇演出臺灣本土故事, 勢必無法避免「語 言錯置」的情形產生。

如第一段含笑與天助「偷來暗去」的情事被養父發現

時, 小說與《梅》劇使用了不同的文字表達。

你看！你們攏總來看！這是啥態度? 我飼養伊十八 冬, 十八冬咧! 未嫁即去討「契兄」, 削世削眾, 削 我十八代祖公的面底皮! ……

莫怪呵！莫怪！叫阿旺嫂來做媒人。「肥肉吞入肚, 嘴才唸阿彌陀！」哼! 不知死活的臭小子, 春秋美夢 還真是敢做！我不會讓伊暢心滿意的。[22]（小說） 含笑養父: 問了半天，這狗賤人一句實話也不說，原 來是陳家這狗雜種幹的好事。我…我非宰了他不 可。……他們陳家破了咱家的門風，壞了咱家的親事， 這輩子想成親, 他們休想。……旺嬸, 你在這山前莊 後, 仔細地打聽打聽, 個人家離此是越遠越好, 只要 給得起豐厚的聘禮, 管他是聾、是瞎、是駝背、是癰 子, 含笑通通嫁, 就是不許嫁陳家。(《梅山春》) 作家王瓊玲在創作小說時, 本著臺灣本土社會環境, 使用臺灣本土語言, 然而搬上舞臺, 卻都成為相異的言語 了。又如演述三段歌仔戲, 皆以「閩南語」演唱, 然而臺 下觀眾卻是講著不同語言, 造成了舞臺上的時空產生錯亂。 「語言錯置」情形，在臺灣豫劇團朝向臺灣本土化的發展 過程中, 是一個急需化解的難題, 亦是不同文化演述過程 中一個不可避免的問題。

\section{5. 結語}

臺灣豫劇團為中國河南地方劇種, 無論是在早期劇本 編排與舞臺表演藝術, 濃厚的「梆子聲腔」以及「虛擬寫 意」的程式化表演是其主要特徵, 然而當臺灣豫劇團開始 逐漸「世界化」與「本土化」的同時, 如何在「傳統程式 藝術」與「現代多元舞臺」相互融合之間取得平衡, 將是 臺灣豫劇團未來發展時的重要課題。而在劇本故事內容面 對「跨文化」與「跨文類」的同時, 如何重構符應戲曲舞 臺表演手法, 不僅是劇本文學的相互融涉再現, 亦是戲曲 舞臺的多元解構。

\section{参考文獻}

［1］王瓊玲.含笑 (M) . 收錄於《美人尖》.臺北: 三民書局股 份有限公司, 2009. 1 初版。

[2] 王瓊玲. 阿惜姨 (M) . 收錄於《駝背漢與花姑娘》. 臺北: 三民書局股份有限公司，2011.2修正。

[3] 王妍方. 心的方向, 家的依歸《梅山春》 $(Z)$ ．「表演藝術 評論臺」, 2014.05.31。

(http://pareviews. ncafroc. org. tw/?p=11083)
４4］紀慧玲. 戲曲 / 映像敘事的雙重解離《梅山春》〔Z 「表 演藝術評論臺」，2014.11.08。

(http://pareviews. ncafroc. org. tw/?p=13497)

[5] 陳芳. 話說「豫莎劇」：從跨文化到現性. 收錄於聲梆。掌 聲（M）. 高雄: 國立傳統藝術中心臺灣豫劇團，2013.10: 14 。

[6] 王瓊玲. 駝背漢與花姑娘 (M). 臺北: 三民書局股份有限公 司, 2011.2修正。

[7］王瓊玲. 美人尖 (M). 臺北: 三民書局股份有限公司, 2009.1 初版。

［8］劉慧芬. 公視《梅山春》訪談 $(Z)$. 2015。

[9］蕭相愷. 美人尖 - 序 (M). 臺北: 三民書局股份有限公司， 2009: 2。

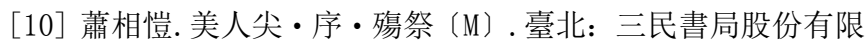
公司, 2009: 2。

[11］李宜樺. 王瓊玲小說集《美人尖》中的臺灣鄉野民俗書寫 ( J ) . 新竹教育大學語文學報. 2011，第17期: 169-170。

[12］王瓊玲. 美人尖-含笑 (M). 臺北: 三民書局股份有限公司, 2009: 14-15。

[13］王瓊玲. 美人尖・含笑 (M) . 臺北: 三民書局股份有限公司， 2009: 9。

[14] 王瓊玲. 駝背漢與花姑娘. 阿惜姨 (M) . 臺北: 三民書局股 份有限公司，2011：97。

[15］王瓊玲. 美人尖・含笑 (M). 臺北: 三民書局股份有限公司, 2009: 13-14。

[16] 李婉君. 美人尖 - 名人推萀三 (M). 臺北: 三民書局股份有 限公司, 2009: 3。

[17］王瓊玲. 美人尖・含笑 (M). 臺北: 三民書局股份有限公司， 2009: 頁18-19。

[18］劉慧芬. 公視《梅山春》訪談 $(Z)$ ．2015。

[19］王瓊玲. 駝背漢與花姑娘 - 阿惜姨 (M) . 臺北: 三民書局股 份有限公司, 2011：96-97。

[20］賴鼎銘. 駝背漢與花姑娘 - 名人推薦二 (M) . 臺北: 三民書 局股份有限公司，2011：5。

[21] 紀慧玲.戲曲 / 映像敘事的雙重解離《梅山春》〔Z 「表 演藝術評論臺」，2014.11.08。

(http://pareviews. ncafroc. org. tw/?p=13497)

[22］王瓊玲. 美人尖・含笑 (M). 臺北: 三民書局股份有限公司， 2009: 14-15。 